\title{
The Western Wind and Solar Integration Study
}

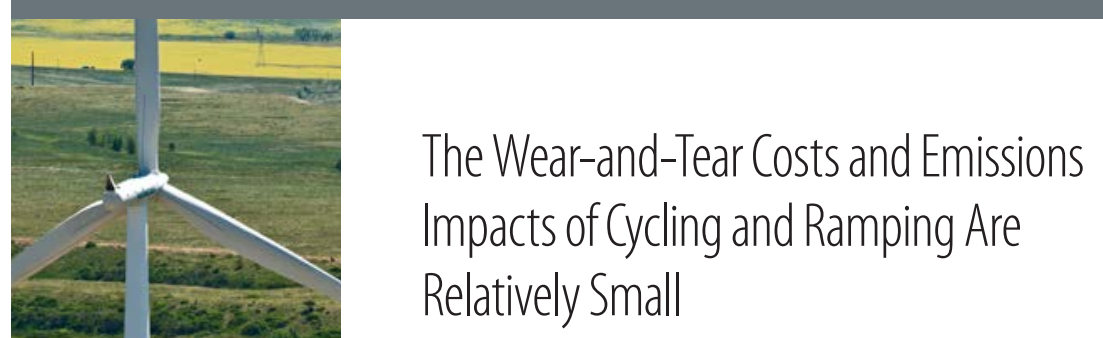

The Western Wind and Solar Integration Study (WWSIS) is one of the largest regional wind and solar integration studies to date. It examines the operational impact of up to $35 \%$ penetration of wind, photovoltaic (PV), and concentrating solar power (CSP) energy on the electric power system. The goal is to understand the effects of and investigate mitigation options for the variability and uncertainty of wind and solar.

\section{Phase 1 Research}

Phase 1 of the Western Wind and Solar Integration Study (WWSIS1) found no technical barriers to the integration of high penetrations of wind and solar power in the Western Interconnection power system if certain changes to operational practices are made. The two most important changes are increased balancing area coordination and sub-hourly scheduling between balancing areas.

High wind and solar output cause coal and other generators to cycle on and off and ramp more frequently. As a result, utilities and policymakers asked the National Renewable Energy Laboratory (NREL) to delve into the details of the impacts of cycling and ramping on wear-and-tear costs and emissions.

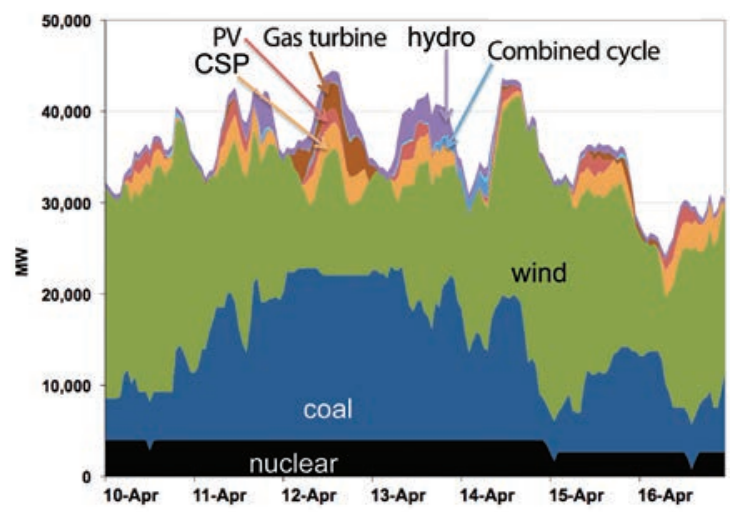

Figure 1. System dispatch for the most challenging week of the three years analyzed.
WWSIS1 considered limited solar penetrations (up to 5\%), and only CSP and rooftop PV were modeled because of limited capabilities to model high-resolution solar PV output on a sub-hourly timescale.

\section{Phase 2 Research}

New techniques allow the Western Wind and Solar Integration Study Phase 2 (WWSIS2) to include high penetrations of solar-not only CSP and rooftop PV but also utility-scale PV plants. WWSIS2 examines:

- What are the wear-and-tear costs of cycling and ramping of coal and gas plants?

- What are the emissions impacts of cycling and ramping of coal and gas plants?

- How should operators re-optimize unit commitment and economic dispatch with these impacts taken into account?

- How do solar impacts compare with those of wind?

- What mitigation options are available?

\section{Wear-and-Tear Cost Data}

Intertek-APTECH provided wear-and-tear cost and impact data for seven categories of fossil-fueled plants, including:

- Coal - small subcritical, large subcritical, and super critical

- Gas - combined cycle, large frame, aeroderivative combustion turbines, and steam.

They also considered "best in class" units for each category.

Data inputs included:

- Costs of hot, warm, and cold starts

- Costs of ramping down to minimum output

- Forced outage rate impacts

- Long-term heat rate degradation.

\section{Ceiling on Wear-and-Tear Costs}

GE Energy applied these wear-and-tear data to the original dispatch results from WWSIS1. Because the wear-and-tear costs were not explicitly modeled in WWSIS1 but will be in WWSIS2, the revised dispatch of WWSIS2 is likely to show less ramping and cycling. Therefore, GE Energy's analysis gives a ceiling on wear-and-tear impacts. 
Results show that cycling costs in the high-renewable scenario have a ceiling of $\$ 0.55 / \mathrm{MWh}$ to $\$ 1.90 / \mathrm{MWh}$ of renewables produced, which is a reduction in the value of the renewables of up to $2.4 \%$.

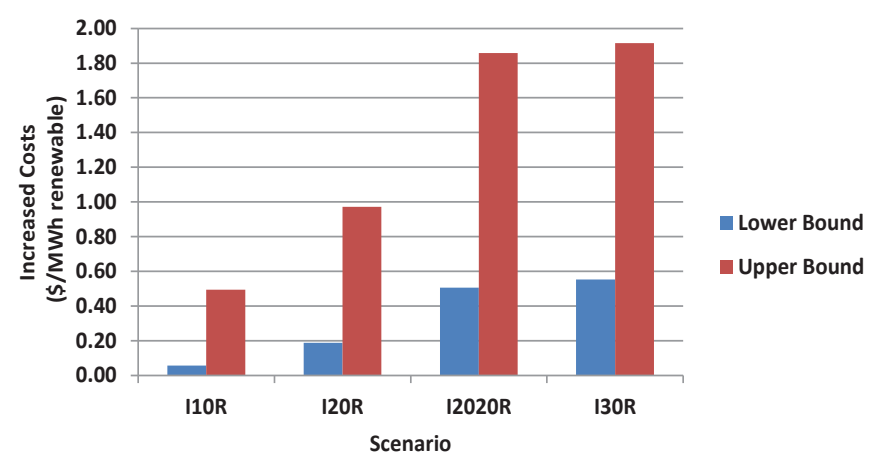

Figure 2. Results show that cycling costs have a ceiling up to \$1.90/MWh of renewables produced, or a reduction in the value of the renewables of up to $2.4 \%$.

\section{Emissions Data}

NREL used the Environmental Protection Agency's Continuous Emissions Monitoring system data set to analyze hourly emissions from nearly every fossil-fired plant in the United States. NREL determined incremental emissions of carbon dioxide, nitrogen oxide, and sulfur dioxide caused by start-ups, ramping, and partial loading.

\section{Emissions Re-Analysis}

NREL applied these detailed start-up, ramping, and partial-loading emissions of nitrogen oxide and carbon dioxide to the dispatch results of WWSIS1. In this re-analysis, generic emission rates - not plant-specific rates - were used for simplicity. The impact of higher-fidelity analysis accounting for start-up, ramping, and partial-loading emissions was relatively small. Avoided carbon dioxide emissions were $1.7 \%$ less, considering the detailed impacts, with the largest impact coming from the partial loading. Avoided nitrogen oxide emissions, on the other hand, were 3.3\% better because of the lower nitrogen oxide rates at partial loading.

Start-ups, partial loading, and ramping have relatively small impact compared with which generation source is being displaced. For example, in WWSIS1, high and low gas prices were compared. High gas prices cause renewables to displace gas, and low gas prices cause renewables to displace coal. The difference in emissions is very large. It can be a factor of two or more.

\section{Conclusions}

NREL found that the wear-and-tear impacts are up to $2.4 \%$ of the value of wind/solar and that the emissions impacts can be either positive or negative and are on the order of a few percent. Next steps include using these new data inputs in security-constrained unit commitment and economic dispatch modeling for the Western Interconnection for four scenarios.
$\mathrm{NO}_{\mathrm{x}}(\mathrm{lbs} / \mathrm{MWh}) \quad \mathrm{CO}_{2}$ (tons/MWh)

\begin{tabular}{|l|c|c|}
\hline Assuming flat emission curves & 0.422 & 0.499 \\
\hline + Considering part-load emission rates & $+0.031(+7.3 \%)$ & $-0.006(-1.3 \%)$ \\
\hline + Considering start-up emissions & $-0.006(-1.3 \%)$ & $-0.001(-0.3 \%)$ \\
\hline + Considering ramping emmissions & $-0.011(-2.7 \%)$ & $-0.001(-0.2 \%)$ \\
\hline Total & $0.436(3.3 \%)$ & $0.490(-1.7 \%)$ \\
\hline
\end{tabular}

Figure 3. Avoided emissions per megawatt-hour of renewable production.

\section{Associated Publications}

GE Energy. (2010). Western Wind and Solar Integration Study. NREL/SR-55047434. Work performed by GE Energy, Schenectady, NY. Golden, CO: National Renewable Energy Laboratory. www.nrel.gov/docs/fy10osti/47434.pdf.

D. Lew, G. Brinkman, E. Ibanez, B.-M. Hodge, and J. King. (2012). "Western Wind and Solar Integration Study Phase 2." Preprint. International Workshop on Integration of Wind Power Into Power Systems as Well as on Transmission Networks for Offshore Wind Power Plants Conference Proceedings, November 13-15, 2012. Golden, C0: National Renewable Energy Laboratory; 9 pp. Accessed September 2012: www.nrel.gov/docs/ fy120sti/56217.pdf.

D. Lew, et al. (2012). "Impacts of Wind and Solar on Fossil-Fueled Generators," Preprint. IEEE Power and Energy Society General Meeting Proceedings, July 22-26, 2012. Golden, C0: National Renewable Energy Laboratory; 10 pp. Accessed September 2012: www.nrel.gov/docs/fy120sti/53504.pdf.

D. Lew, et al. (2012). "Sub-Hourly Impacts of High Solar Penetrations in the Western United States." Preprint. International Workshop on Integration of Solar Power Into Power Systems Conference Proceedings, November 12-13, 2012. Golden, C0: National Renewable Energy Laboratory; 11 pp. Accessed September 2012: www.nrel.gov/docs/fy120sti/56171.pdf.

\section{More Information}

Debra Lew, 303-384-7037, debra.lew@nrel.gov

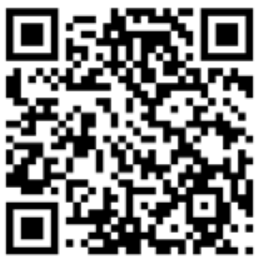

See our website at www.nrel.gov/electricity/transmission/.

Photos (from top): Photo by Pat Corkery, NREL/PIX 17721; photo by SunEdison, NREL/PIX 17423; photo by Pat Corkery, NREL/PIX 16142; photo by Dennis Schroeder, NREL/PIX 19176
NREL is a national laboratory of the U.S. Department of Energy, Office of Energy Efficiency and Renewable Energy, operated by the Alliance for Sustainable Energy, LLC.

NREL/FS-5500-55999 • September 2012 